\title{
Study of early perinatal outcome in lower segment caesarean section in severe foetal distress at tertiary care centre
}

\author{
Chandrakant A. Jadhav*, Tirankar V. R., Gavandi P. S.
}

Department of Obstetrics and Gynecology, Dr. V. M. Government Medical College. Solapur, Maharashtra, India

Received: 04 July 2019

Revised: 27 January 2020

Accepted: 01 February 2020

\section{*Correspondence:}

Dr. Chandrakant A. Jadhav,

E-mail: drchand007@gmail.com

Copyright: () the author(s), publisher and licensee Medip Academy. This is an open-access article distributed under the terms of the Creative Commons Attribution Non-Commercial License, which permits unrestricted non-commercial use, distribution, and reproduction in any medium, provided the original work is properly cited.

\section{ABSTRACT}

Background: For asphyxia, the fetus reacts with a series of responses. First there is redistribution of blood flow to vital centres to limit the deleterious effects of oxygen limitation in the brain, heart and adrenal glands. A further compensatory response is that overall fetal oxygen consumption declines to values as low as $50 \%$ of the control.

Methods: This was a prospective study. Early perinatal outcome of newborns delivered through Caesarean section due to clinical foetal distress in labour was compared with a group of newborns similarly delivered via Caesarean section without a diagnosis of clinical foetal distress. Data collected and analysed using appropriate standard statistical methods i.e. Chi-square $\left(\mathrm{X}^{2}\right)$ test and ' $\mathrm{Z}$ ' - test.

Results: Most common indication for NICU admission in study group was MAS (Meconium Aspiration Syndrome $14 \%$ ) followed by MAS with perinatal asphyxia (5.33\%), MAS with Hypoxic ischaemic encephalopathy (HIE) - stage III $(3.33 \%)$ paerintal asphyxia (2.66\%), severe PNA with HIE - III $(0.66 \%)$ and TTN $(0.66 \%)$ meconium gastritis $(0.66 \%)$ respectively.

Conclusions: Clinical foetal distress (study group) was found to be significantly associated with low 1 min and 5 min. Apgar score. There was no significant difference in immediate NICU admission whether D-D (i.e. detection fetal detection to delivery interval) time interval $<30$ minutes or $>30$ minutes. But rate of mortality was high when D-D (i.e. detection fetal detection to delivery interval) was $>30$ minutes.

Keywords: Apgar score, Foetal distress, Caesarean section, Hypoxic ischaemic encephalopathy, Meconium aspiration syndrome, Perinatal outcome

\section{INTRODUCTION}

The fetus depend on the mother for exchange of oxygen and carbon dioxide is reliant on adequate maternal blood gas concentrations, uterine blood supply, placental transfer and fetal gas transport. ${ }^{1,2}$

For asphyxia, the fetus reacts with a series of responses. First there is redistribution of blood flow to vital centres to limit the deleterious effects of oxygen limitation in the brain, heart and adrenal glands. A further compensatory response is that overall fetal oxygen consumption declines to values as low as $50 \%$ of the control. This level can be maintained for periods up to 45 minutes and is completely reversible on cessation of hypoxia. ${ }^{3}$ There is accumulation of lactate in the vascular beds with limited oxygen supply due to anaerobic glycolysis leading to gradual development of metabolic acidosis., ${ }^{4,5}$

The management of the compromised fetus is a challenging task and often prompts performance of an emergency caesarean delivery. Fetal distress is a poorly 
defined term and may result in unnecessary emergency caesarean deliveries under general anesthesia. ${ }^{4}$

The goal of fetal intrapartum resuscitation (FIR) is to optimize the fetal condition in utero so that labor may continue safely, or to improve fetal wellbeing prior to emergency delivery. Intrauterine resuscitation encompasses maternal repositioning, reducing uterine activity, oxygen administration, amnioinfusion, optimizing aternal fluid status and correction of hypotension, and modifying maternal expulsive efforts. It helps to "buy time" to optimize the fetal condition while preparing for an impending delivery, or an emergency cesarean section. ${ }^{1}$

\section{Meconium aspiration syndrome (MAS)}

Meconium staining is, in itself, not evidence that the foetus is suffering from oxygen deprivation in the uterus. There is a suggestion that the foetus passes the meconium because it is under stress however the main concern is related to meconium aspiration syndrome, which is where the baby takes meconium contaminated fluid into its lungs either before or during birth. This is more common in post term babies (over 41 weeks) and is rare before 38 weeks. ${ }^{6}$

MAS causes problems in breathing through two means; there is some evidence that indicates that meconium inhibits, or depletes, the function of the surfactant (a naturally produced soapy substance that stops the walls of the lung buds from sticking to each other) which makes breathing ineffective. The second problem caused is that the meconium can block the lungs thus reducing the amount of oxygen that can be taken in. Meconium also causes irritation in the lungs that can lead to inflammation and infection and potentially death of the affected areas of lung tissue. ${ }^{7}$

\section{Intrapartum fetal resuscitation ${ }^{1}$}

The goal of fetal intrapartum resuscitation (FIR) is to optimize the fetal condition in utero so that labor may continue safely, or to improve fetal wellbeing prior to emergency delivery. ${ }^{1}$

\section{Maternal oxygenation}

Maternal oxygen administration has been used in an attempt to reduce fetal distress by increasing the available oxygen from the mother. Even though healthy women in labor have high blood oxygen saturation $\left(\mathrm{SpO}_{2}\right)$, it has been suggested that increasing inspired $\mathrm{O}_{2}$ increases blood $\mathrm{O}_{2}$ tension and results in more $\mathrm{O}_{2}$ delivered to the fetus. $^{8}$

\section{Improving blood supply to the uterus}

Maternal body position can influence fetal well-being without uterine contractions; results of non-stress tests
(NST) are most unfavourable when mothers lie on their back.9-11 'Aortocaval compression' describes compression of the inferior vena cava and the aorta by the gravid uterus in women at term. ${ }^{12,13}$ Acute fetal distress can be caused by either hypoperfusion of the uteroplacental unit secondary to maternal hypotension, or occult aortic compression causing a reduction in iliac arterial flow. The compression of the aorta by the pregnant uterus decreases the blood pressure and especially, pulse pressure distal to the affected level (supine hypotensive syndrome). Maternal cardiovascular compromise and fetal stress in maternal supine position and their relief in the full lateral position, are well recognized. ${ }^{14-16}$ Inferior vena cava compression is demonstrable up to $12.5^{0}-15^{0}$ of lateral tilt and aortic compression up to $30^{\circ}$. The use of $15^{\circ}$ of tilt at cesarean section and $30^{\circ}$ during labor reduces the effects considerably. This amount of tilt, if applied correctly, reduces inferior vena cava compression. ${ }^{17}$

\section{Intravenous fluids}

Animal studies have shown that boluses of intravenous crystalloids increased maternal arterial blood pressure and placental site blood flow and decreased vascular resistance, however, there was no rise in fetal $\mathrm{PO}_{2} .{ }^{18} \mathrm{In}$ hypovolemic or hypotensive women, blood volume shifts away from the uterus affecting oxygen delivery to the fetus. A bolus of $500 \mathrm{ml}$ of lactated Ringer's solution over 20 minutes significantly increases fetal oxygen saturation.

\section{Improving placental perfusion}

Uterine contractions cause a cessation of maternal intervillous placental blood flow resulting in relative fetal hypoxia with recovery taking 60-90 seconds. ${ }^{19}$ If this intermittent interruption of blood flow becomes too frequent the fetus is at risk for hypoxemia and acidosis.

Briozzo et al, conducted a prospective randomized study to determine whether FIR using tocolysis and delayed delivery was better for the fetus than emergency delivery when fetal hypoxia was suspected because of a nonreassuring FHR pattern using conventional heart rate monitoring. ${ }^{20}$ They concluded that tocolysis and delayed delivery rendered better immediate neonatal results than emergency delivery when fetal distress was suspected because of a non-reassuring fetal heart pattern. In addition, it may decrease the need for emergency delivery without increasing maternal and fetal adverse sideeffects.

\section{Improving funic blood flow}

Amnioinfusion prevents or relieves umbilical cord compression usually caused by oligohydramnios. Amnioinfusion has been shown to reduce the incidence of variable fetal heart decelerations, but not late decelerations or reduced variability. ${ }^{21-23}$ 


\section{METHODS}

This was a prospective study. Early perinatal outcome of newborns delivered through caesarean section due to clinical foetal distress (on the bases of abnormal foetal heart rate and rhythm by intermittent auscultation, together with meconium staining of amniotic fluid) in labour was compared with a group of newborns similarly delivered via caesarean section without a diagnosis of clinical foetal distress (The non - exposed group of mothers comprises of mothers who underwent caesarean section for indications other than clinical diagnosis of foetal distress). Data collected and analysed using appropriate standard statistical methods i.e. Chi-square $\left(\mathrm{X}^{2}\right)$ test and ' $\mathrm{Z}$ ' - test.

\section{Inclusion criteria}

- Term gestation (at 37 weeks or above)

- Cephalic presentation

- Singleton pregnancies.

\section{Exclusion criteria}

- All patients with diagnosis of intra- uterine fetal death (IUFD)

- Multiple gestations

- Low birth weight (less than $1.8 \mathrm{~kg}$ )

- Malpresentation.

\section{After the extraction of baby (by LSCS) we studied following things}

- Relationship between clinical fetal distress and oneminute Apgar score

- Relationship between clinical fetal distress and fiveminute Apgar score

- Clinical foetal distress and foetal outcome during the first 24 hours post-partum

- Distribution of reasons for admission to new-born unit for more than 24 hours to 48 hours
- Relationship between clinical foetal distress and morbidity and mortality

- Perinatal outcome at 48 hours

- Take home baby rate.

This study was performed in 150 pregnant women who had completed 37 weeks of gestation and underwent lower segment caesarean section for clinical foetal distress in labour (study group) was compared with another 150 pregnant women who had completed 37 weeks of gestation who underwent lower segment caesarean section for indication other than clinical foetal distress (control group).

\section{RESULTS}

Majority of the patients were in the age group of 21-25 years in both study (54\%) and control group (57.33\%).

Table 1: Age distribution.

\begin{tabular}{|ll|l|}
\hline Age (years) & $\begin{array}{l}\text { Study group } \\
(\mathbf{1 5 0})\end{array}$ & $\begin{array}{l}\text { Control group } \\
(\mathbf{1 5 0})\end{array}$ \\
\hline $18-20$ & $45(30 \%)$ & $28(18.66 \%)$ \\
\hline $21-25$ & $81(54 \%)$ & $86(57.33 \%)$ \\
\hline $26-30$ & $17(11.33 \%)$ & $32(21.33 \%)$ \\
\hline$>30$ & $7(04.6 \%)$ & $4(02.66 \%)$ \\
\hline Mean \pm SD & $\mathbf{2 3 . 0 5} \pm \mathbf{3 . 6 3}$ & $\mathbf{2 3 . 9 1} \pm \mathbf{3 . 4 3}$ \\
\hline
\end{tabular}

'p' value - $p>0.05$ (insignificant).

Table 2: Gravidity distribution.

\begin{tabular}{|lll|}
\hline Gravidity & $\begin{array}{l}\text { Study group } \\
(\mathbf{1 5 0 )}\end{array}$ & $\begin{array}{l}\text { Control group } \\
(\mathbf{1 5 0})\end{array}$ \\
\hline Gravida 1 & $80(53.33 \%)$ & $42(28 \%)$ \\
\hline Gravida 2 & $42(28 \%)$ & $62(41.33 \%)$ \\
\hline Gravida 3 & $23(15.33 \%)$ & $33(22 \%)$ \\
\hline Gravida 4 & $4(2.6 \%)$ & $11(7.33 \%)$ \\
\hline Gravida 5 & $0(0 \%)$ & $2(1.33 \%)$ \\
\hline Gravida 6 & $1(0.66 \%)$ & $0(0 \%)$ \\
\hline
\end{tabular}

Table 3: Antenatal complications (risk factors).

\begin{tabular}{|lll|}
\hline Complications & Study group & Control group \\
\hline Pregnancy induced hypertension & $25(16.66 \%)$ & $25(16.66 \%)$ \\
\hline Anemia & $38(25.33 \%)$ & $25(16.66 \%)$ \\
\hline Anemia with PIH & $3(2 \%)$ & $2(1.33 \%)$ \\
\hline Post maturity (41 weeks and above) & $38(25.33 \%)$ & $10(6.66 \%)$ \\
\hline Oligohydramnios & $3(2 \%)$ & $1(0.66 \%)$ \\
\hline Abruptio placentae & $2(1.33 \%)$ & $0(0 \%)$ \\
\hline Central placenta previa & $1(0.66 \%)$ & $2(1.33 \%)$ \\
\hline Antepartum eclampsia & $0(0 \%)$ & $2(1.33 \%)$ \\
\hline PROM & $8(5.33 \%)$ & $15(10 \%)$ \\
\hline Mother on anti-convulsant/ anti-psychotic drug & $2(1.33 \%)$ & $0(0 \%)$ \\
\hline Total & $\mathbf{1 2 0 ( 8 0 \% )}$ & $\mathbf{8 2 ( 5 4 . 6 6 \% )}$ \\
\hline
\end{tabular}

$\mathrm{p}<0.01$ (more significant). 
Table 4: Distribution of 1 min Apgar score in study and control group.

\begin{tabular}{|lllll|r|} 
& $\mathbf{0 - 3}($ Very poor) & 4-6 (Moderate poor) & 7-10 (Good) & Mean \pm SD & \\
\hline Study group (150) & $27(18 \%)$ & $90(60 \%)$ & $33(22 \%)$ & $5.21 \pm 1.6$ & 'p' value $-\mathrm{p}<0.001$ \\
\hline Control group $(150)$ & $3(2 \%)$ & $46(30.66 \%)$ & $101(67.33 \%)$ & $7.09 \pm 1.11$ & (highly significant) \\
\hline
\end{tabular}

Table 5: Distribution of 5 min Apgar score in study group and control group.

\begin{tabular}{|c|c|c|c|c|c|}
\hline & 0-3 (Very poor) & 4-6 (Moderate poor) & 7-10 (Good) & Mean \pm SD & \\
\hline Study group (150) & $11(7.33 \%)$ & $26(17.33 \%)$ & $113(75.33 \%)$ & $6.99 \pm 1.75$ & \multirow{2}{*}{$\begin{array}{l}\text { 'p' value }-\mathrm{p}<0.001 \\
\text { (highly significant) }\end{array}$} \\
\hline Control group (150) & $0(0 \%)$ & $03(2 \%)$ & $147(98 \%)$ & $8.19 \pm 0.81$ & \\
\hline
\end{tabular}

Table 6: Distribution of liquor state Apgar score and fetal outcome in study group.

\begin{tabular}{|lllllll|}
\hline Liquor state & No. of cases & Low Apgar score (0-6) & $\begin{array}{l}\text { Admission to NICU } \\
\text { in first } \mathbf{4 8} \text { hours }\end{array}$ & $\begin{array}{l}\text { Discharge } \\
\text { rate }\end{array}$ & $\begin{array}{l}\text { Mortality } \\
\text { (death) }\end{array}$ \\
\hline Thin meconium & $61(40.66 \%)$ & $39(26 \%)$ & $5(3.33 \%)$ & $6(4 \%)$ & $6(4 \%)$ & $0(0 \%)$ \\
\hline Thick meconium & $79(52.66 \%)$ & $70(46.6 \%)$ & $29(19.33 \%)$ & $32(21.33 \%)$ & $19(12.66 \%)$ & $\begin{array}{l}13+2 \text { still birth } \\
=15(10 \%)\end{array}$ \\
\hline Clear & $9(6 \%)$ & $7(4.66 \%)$ & $2(1.33 \%)$ & $2(1.33 \%)$ & $1(0.66 \%)$ & $1(0.66 \%)$ \\
\hline Blood tinged & $1(0.66 \%)$ & $1(0.66 \%)$ & $1(0.66 \%)$ & $1(0.66 \%)$ & $1(0.66 \%)$ & $0(0 \%)$ \\
\hline Total & $\mathbf{1 5 0}$ & $\mathbf{1 1 7}$ & $\mathbf{3 7}$ & $\mathbf{4 1}$ & $\mathbf{2 7}$ & $\mathbf{1 6}$ \\
\hline
\end{tabular}

Table 7: Distribution of fetal outcome in study group.

\begin{tabular}{|c|c|c|c|c|c|c|}
\hline & $\begin{array}{l}\text { No. of } \\
\text { admission } \\
\text { to NICU }\end{array}$ & \multicolumn{2}{|l|}{$\begin{array}{l}\text { Reason for admission to } \\
\text { NICU }\end{array}$} & Discharge & Mortality & Cause of deaths \\
\hline \multirow{3}{*}{$\begin{array}{l}0-24 \\
\text { hours }\end{array}$} & \multirow{3}{*}{$\begin{array}{l}41 \\
(27.33 \%)\end{array}$} & \multirow{3}{*}{\multicolumn{2}{|c|}{$\begin{array}{l}\text { MAS } \longrightarrow 21(14 \%) \\
\text { MAS with PNA } \longrightarrow 8(5.33 \%) \\
\text { Perinatal Asphyxia } \longrightarrow 4(2.66 \%) \\
\text { Severe PNA with HIE-III } \longrightarrow 1(0.66 \%) \\
\text { MAS with HIE-III } \longrightarrow 5(3.33 \%) \\
\text { TTN } \longrightarrow 1(0.66 \%) \\
\text { Meconium gastritis } \longrightarrow 1(0.66 \%)\end{array}$}} & & \multirow{3}{*}{$\begin{array}{l}3+2 \mathrm{SB}=5 \\
(3.33 \%)\end{array}$} & $\begin{array}{l}\text { MAS with pulmonary } \\
\text { hemorrhage with RF with RD }\end{array}$ \\
\hline & & & & & & MAS with severe PNA \\
\hline & & & & & & MAS with severe PNA \\
\hline \multirow{3}{*}{$\begin{array}{l}25-48 \\
\text { hours }\end{array}$} & \multirow{3}{*}{-} & \multirow{3}{*}{-} & \multirow{3}{*}{-} & \multirow{3}{*}{$2(1.33 \%)$} & \multirow{3}{*}{$3(2 \%)$} & MAS with HIE-III severe PNA \\
\hline & & & & & & MAS with HIE-III \\
\hline & & & & & & Severe PNA with HIE-III \\
\hline $\begin{array}{l}49-72 \\
\text { hours }\end{array}$ & $2(1.33 \%)$ & $\begin{array}{l}\text { Aspiration pneumonitis } \\
\text { with RD } \\
\text { Hypoglycemic convulsion }\end{array}$ & $\begin{array}{l}1 \\
1\end{array}$ & $2(1.33 \%)$ & $2(1.33 \%)$ & $\begin{array}{l}\text { MAS with HIE-III with severe } \\
\text { PNA }\end{array}$ \\
\hline \multirow{6}{*}{$\begin{array}{l}73 \\
\text { hours } \\
\text { to } 7 \\
\text { days }\end{array}$} & \multirow{3}{*}{$3(2 \%)$} & \multirow{3}{*}{$\begin{array}{l}\text { Jaundice } \\
\text { (Hyperbilirubinemia) } \\
\text { (on PND4) } \\
\text { Hypoglycemic convulsion } \\
\text { (on PND 4) }\end{array}$} & \multirow[t]{2}{*}{2} & \multirow{3}{*}{$\begin{array}{l}4(2.66 \%) \\
\text { (PND4) }\end{array}$} & \multirow{3}{*}{$\begin{array}{l}3(2 \%) \\
(\mathrm{PND} 4)\end{array}$} & $\begin{array}{l}\text { MAS with HIE-III with severe } \\
\text { PNA with RF with } \\
\text { cardiorespiratory arrest (CRA) }\end{array}$ \\
\hline & & & & & & $\begin{array}{l}\text { MAS with HIE-III with RF } \\
\text { with CRA }\end{array}$ \\
\hline & & & 1 & & & $\begin{array}{l}\text { MAS with pulmonary } \\
\text { hemorrhage with severe } \\
\text { perinatal asphyxia }\end{array}$ \\
\hline & & & & \multirow{2}{*}{$\begin{array}{l}\text { PND } 5-7 \\
(4.66 \%)\end{array}$} & \multirow[t]{2}{*}{$2(1.33 \%)$} & $\begin{array}{l}\text { Aspiration pneumonitis with } \\
\text { RD with RF with CRA }\end{array}$ \\
\hline & & & & & & MAS with HIE stage III \\
\hline & & & & $\begin{array}{l}\text { PND 6-2 } \\
(1.33 \%)\end{array}$ & $1(0.66 \%)$ & MAS with severe PNA \\
\hline \multicolumn{2}{|c|}{$>7$ days } & & & $12(8 \%)$ & $\begin{array}{l}1(0.66 \%) \\
\text { (on PND8) }\end{array}$ & MAS with RF with CRA \\
\hline
\end{tabular}


Association of primigravida in study group was statistically highly significant $(p<0.001)$ when compared with control group.

Anemia $(25.33 \%)$ and post-maturity (41 weeks and above) (25.33\%) was most common antenatal complications in study group. 2nd common complication in study group was pregnancy induced hypertension $(16.66 \%)$.

Incidence of low 1 min Apgar score i.e. very poor (18\%) and moderately poor $(60 \%)$ was higher in study group when compared with control group in which incidence of low 1 min Apgar score was very poor (2\%) and moderately poor $(30.66 \%)$.

Incidence of low 5 min Apgar score i.e. very poor $(7.33 \%)$ and moderately poor $(17.33 \%)$ was higher in study group when compared with control group in which incidence of low 5 min Apgar score was very poor (0\%), moderately poor $(2 \%)$.
In control group incidence of good Apgar score at 5 min was higher (98\%) when compared with study group $(75.33 \%)$.

Association of low 5 min. Apgar score in study group was statistically highly significant $(\mathrm{p}<0.001)$.

Rate of NICU admission in first 48 hrs. was higher in thick meconium stained liquor group i.e. $21.33 \%$ followed by thin meconium (4\%), clear liquor $(1.33 \%)$, Blood tinged liquor $(0.66 \%)$ respectively.

Most common indication for NICU admission in study group was MAS (meconium aspiration syndrome 14\%) followed by MAS with perinatal asphyxia (5.33\%), MAS with hypoxic ischaemic encephalopathy (HIE) - stage III $(3.33 \%)$ paerintal asphyxia $(2.66 \%)$, severe PNA with HIE - III $(0.66 \%)$ and TTN $(0.66 \%)$ meconium gastritis $(0.66 \%)$ respectively.

Table 8: Distribution of fetal outcome in control group.

\begin{tabular}{|c|c|c|c|c|c|c|}
\hline & $\begin{array}{l}\text { No. of admission } \\
\text { to NICU }\end{array}$ & Reason for admission & & Discharge & Mortality & $\begin{array}{l}\text { Cause of } \\
\text { deaths }\end{array}$ \\
\hline \multirow{5}{*}{$0-24$ hours } & \multirow{5}{*}{$6(4 \%)$} & Cleft lip and cleft palate & $1(0.66 \%)$ & \multirow{5}{*}{-} & \multirow{5}{*}{-} & \multirow{5}{*}{-} \\
\hline & & Anal atresia & $1(0.66 \%)$ & & & \\
\hline & & $\mathrm{MgSO}_{4}$ depression & $2(1.33 \%)$ & & & \\
\hline & & Moderate PNA & $1(0.66 \%)$ & & & \\
\hline & & Severe PNA? Heart disease & $1(0.66 \%)$ & & & \\
\hline 25-48 hours & - & - & - & - & - & - \\
\hline 49-72 hours & $1(0.66 \%)$ & Jaundice & $1(0.66 \%)$ & $2(1.33 \%)$ & - & - \\
\hline$>7$ days & - & - & - & $5(3.33 \%)$ & & \\
\hline
\end{tabular}

Table 9: Fetal outcome in first 48 hours in study group and control group.

\begin{tabular}{|llll|}
\hline & Baby with mother & Admitted in NICU & Mortality \\
\hline Study group & $109(72.66 \%)$ & $41(27.33 \%)$ & $6+2$ SB (still birth $)=8(5.33 \%)$ \\
\hline Control group & $144(96 \%)$ & $6(4 \%)$ & $0(0 \%)$ \\
\hline
\end{tabular}

'p' value - $p<0.001$ (highly significant).

Table 10: Fetal outcome in relation to detection of fetal distress to delivery interval in study group.

\begin{tabular}{|llll|}
\hline detection of fetal distress to delivery interval & No. of LSCS & NICU admission & Mortality \\
\hline \multirow{2}{*}{$\leq 30 \mathrm{~min}$} & $60(40 \%)$ & $16(60)$ & $3+2$ still births $=5$ \\
& $(\mathrm{n}=150)$ & $(26.66 \%)$ & $(60)(8.33 \%)$ \\
\hline \multirow{2}{*}{$>30 \mathrm{~min}$} & $90(60 \%)$ & $25(90)$ & $11(90)$ \\
& $(\mathrm{n}=150)$ & $(27.77 \%)$ & $(12.22 \%)$ \\
\hline
\end{tabular}

And most common cause for perinatal deaths in study group was MAS with HIE stage III with severe PNA $(2.66 \%), 2^{\text {nd }}$ common cause for perinatal death was MAS with severe PNA $(2 \%)$ and MAS with HIE stage III ( $2 \%)$ followed by MAS with pulmonry haemorrhage with RD with RF (0.66\%), severe PNA with HIE stage III
(0.66\%), MAS with pulmonary haemorrhage with sever perinatal asphyxia $(0.66 \%)$, Aspiration pneumonitis with RD with RF with cardiorespiratory arrest $(0.66 \%)$ and MAS with RF with cardiorespiratory arrest $(0.66 \%)$ respectively. 
Incidence of NICU admission rate $(27.33 \%)$, and mortality $(5.33 \%)$ was higher in study group in first 48 hours, when compared to control group NICU admission rate was $(4 \%)$ but no mortality.

In control group incidence of baby with mother was higher (96\%) when compared with study group (72.66\%).

Admission to NICU, mortality rate was statistically highly significant in study group when compared to control group $(p<0.001)$ in first 48 hours.

Incidence of NICU admission rate (27.33\%), and mortality $(5.33 \%)$ was higher in study group in first 48 hours., when compared to control group NICU admission rate was $(4 \%)$ but no mortality.

In control group incidence of Baby with mother was higher (96\%) when compared with study group (72.66\%).
Admission to NICU, mortality rate was statistically highly significant in study group when compared to control group $(\mathrm{p}<0.001)$ in first 48 hours.

Incidence of NICU admission (27.77\%), and mortality $(12.22 \%)$ was more when lower segment caesarean section was done after $30 \mathrm{~min}$ of detection of fetal distress.

\section{DISCUSSION}

The outcomes of various studies were comparable.

Majority of the patient in both present study (95\%) and A. Geidam study $(85 \%)$ were in age group $20-35$ years.

This age group represents the reproductive active age group in general.

Table 11: Age distribution: comparison of present study with A. Geidam, B. Bako, S. Ibhrahim, M. Ashir. ${ }^{24}$

\begin{tabular}{|ll|ll|}
\hline Age distribution & Age (years) & Study group & Control group \\
\hline \multirow{3}{*}{ Geidam A study $(\mathrm{n}=120)$} & $<20$ years & $11(9.1 \%)$ & $11(9.1 \%)$ \\
\cline { 2 - 4 } & $20-35$ & $102(85 \%)$ & $100(83.33 \%)$ \\
\cline { 2 - 4 } & $>35$ & $7(5.83 \%)$ & $9(7.5 \%)$ \\
\hline \multirow{3}{*}{ Present study $(\mathrm{n}=150)$} & $<20$ & $6(4 \%)$ & $6(4 \%)$ \\
\cline { 2 - 4 } & $20-35$ & $143(95 \%)$ & $143(95 \%)$ \\
\cline { 2 - 4 } & $>35$ & $1(0.66 \%)$ & $1(0.66 \%)$ \\
\hline
\end{tabular}

Table 12: Gravidity distribution: comparison of present study with A. Geidam, B. Bako, S. Ibhrahim, M. Ashir study in terms of gravidity. ${ }^{24}$

\begin{tabular}{|llll|}
\hline Gravidity Distribution & Gravidity & Study group & Control group \\
\hline \multirow{3}{*}{ Geidam A. study $(\mathrm{n}=120)$} & Primigravida & $57(47.5 \%)$ & $56(46.66 \%)$ \\
\cline { 2 - 4 } & $2^{\text {nd }}$ to 5 $5^{\text {th }}$ gravida & $55(45.83 \%)$ & $56(46.66 \%)$ \\
\cline { 2 - 4 } & Gravida 6th and above & $8(6.66 \%)$ & $8(6.66 \%)$ \\
\hline \multirow{3}{*}{ Present study $(\mathrm{n}=150)$} & Primigravida & $80(53.33 \%)$ & $42(28 \%)$ \\
\cline { 2 - 4 } & $2^{\text {nd }}$ to 5 $5^{\text {th }}$ gravida & $69(46 \%)$ & $108(72 \%)$ \\
\cline { 2 - 4 } & Gravida 6th and above & $1(0.66 \%)$ & $0(0.00 \%)$ \\
\hline
\end{tabular}

Table 13: Antenatal complications (risk factor), comparison of present study with A. Geidam, B. Bako, S. Ibhrahim, M. Ashir study. ${ }^{24}$

\begin{tabular}{|c|c|c|c|}
\hline & Antenatal complication & Study group & Control group \\
\hline \multirow{3}{*}{$\begin{array}{l}\text { Geidam A. study } \\
(\mathrm{n}=120)\end{array}$} & Eclampsia /PIH & $7(5.83 \%)$ & $11(9 \%)$ \\
\hline & Placenta previa & $0(0.0 \%)$ & $4(3.33 \%)$ \\
\hline & Abruptio placentae & $2(1.66 \%)$ & $0(0.0 \%)$ \\
\hline \multirow{3}{*}{$\begin{array}{l}\text { Present study } \\
(\mathrm{n}=150)\end{array}$} & Eclampsia/PIH & $25(16.66 \%)$ & $25(16.66 \%)$ \\
\hline & Placenta Previa & $1(0.66 \%)$ & $2(1.33 \%)$ \\
\hline & Abruption placenta & $2(1.33 \%)$ & $0 .(0.0 \%)$ \\
\hline
\end{tabular}

In present study $(53.33 \%)$ and A. Geidam study $(47.5 \%)$ majority of the patient in study group were primigravida.
In present study anemia $(25.33 \%)$ and post-maturity (41 week and above) (25.33\%) were most common antenatal complications in study group. 
In control group anemia $(16.66 \%)$ and pregnancy induced hypertension $(16.66 \%)$ were most common antenatal complications.
Association of above various antenatal complications were significant in meconium stained liquor.

Table 14: Association of maternal antenatal complications in meconium stained liquor.

\begin{tabular}{|lll|}
\hline Antenatal complications & Bhinde SS, Baxi SR study ${ }^{25}(\mathbf{n}=\mathbf{1 7 4})$ & Present study $(\mathbf{n}=\mathbf{1 5 0})$ \\
\hline Anemia & $30(17.24 \%)$ & $37(24.66 \%)$ \\
\hline PIH & $24(13.8 \%)$ & $24(16.00 \%)$ \\
\hline PROM & $13(7.47 \%)$ & $8(5.33 \%)$ \\
\hline Antepartum haemorrhage & $5(2.87 \%)$ & $3(2 \%)$ \\
\hline Postmaturity (41 weeks and above) & - & $34(22.66 \%)$ \\
\hline Oligohydramnios & - & $3(2 \%)$ \\
\hline
\end{tabular}

Table 15: Incidence of low 1 min Apgar score.

\begin{tabular}{|llll|}
\hline \multirow{3}{*}{ Kenyatta hospital study } & Apgar score & Study group & Control group \\
& $0-3($ Very poor) & $7(12 \%)$ & $0(0 \%)$ \\
\cline { 2 - 4 } & 4-6 (Moderately poor) & $27(47 \%)$ & $18(31 \%)$ \\
\cline { 2 - 4 } & $7-10($ Good) & $24(41 \%)$ & $40(69 \%)$ \\
\hline \multirow{3}{*}{ Present study $(\mathrm{n}=150)$} & $0-3($ Very poor) & $27(18 \%)$ & $03(2 \%)$ \\
\cline { 2 - 4 } & 4-6 (Moderately poor) & $90(60 \%)$ & $46(30.66 \%)$ \\
\cline { 2 - 4 } & $7-10($ Good) & $33(22 \%)$ & $101(67.33 \%)$ \\
\hline
\end{tabular}

Table 16: Incidence of low 5 min Apgar score (0-6).

\begin{tabular}{|lll|}
\hline & $\begin{array}{l}\text { Study } \\
\text { group }\end{array}$ & $\begin{array}{l}\text { Control } \\
\text { group }\end{array}$ \\
\hline $\begin{array}{l}\text { Kenyatta hospital study } \\
(\mathrm{n}=58)\end{array}$ & $14(24.1 \%)$ & $2(3.4 \%)$ \\
\hline Geidam A. study ${ }^{24}(\mathrm{n}=120)$ & $17(14.16 \%)$ & $5(4.16 \%)$ \\
\hline Roy KK study ${ }^{27}(\mathrm{n}=217)$ & $15.2 \%$ & - \\
\hline Present study $(\mathrm{n}=150)$ & $37(24.66 \%)$ & $03(2 \%)$ \\
\hline
\end{tabular}

In present study most common complication associated with meconium stained liquor was Anemia (24.66\%) and post maturity $(22.66 \%)$ followed by PIH (16.00\%).

Results of present study was comparable with the report of Bhinde SS, Baxi SR study. ${ }^{25}$

Table 17: Incidence of NICU admission in first 24 hours of birth.

\begin{tabular}{|ll|l|}
\hline $\begin{array}{l}\text { Kenyatta hospital } \\
\text { study }^{26}(\mathrm{n}=58)\end{array}$ & Study group & Control group \\
\hline $\begin{array}{l}\text { Roy KK study } \\
\text { Monitoring) }(\mathrm{n}=217)\end{array}$ & $15.2 \%$ & $10(17 \%)$ \\
\hline Present study $(\mathrm{n}=150)$ & $41(27.33 \%)$ & - \\
\hline
\end{tabular}

Association of low 1 min Apgar score in study group was high and significant, when compared to control group. Clinical diagnosis of foetal distress was found to be associated with low 1 min Apgar score in present study and comparable with the report of Kenyatta hospital study. ${ }^{8}$

Clinical diagnosis of foetal distress was found to be significantly associated with low 5 minutes Apgar score in present study and was comparable with the reports of Kenyatta hospital study, A. Geidam study, Roy KK study.

Incidence of NICU admission in Kenyatta hospital study, Roy KK study and present study was higher in study group when compared to control group.

Clinical diagnosis of foetal distress was found to be significantly associated with high NICU admission in present study and was comparable with Kenyatta hospital study. ${ }^{26}$

Table 18: NICU admission in relation to detection of fetal distress to delivery interval.

\begin{tabular}{|lll|}
\hline & $\begin{array}{l}\text { Detection of fetal } \\
\text { distress to delivery } \\
\text { interval }\end{array}$ & $\begin{array}{l}\text { NICU } \\
\text { admission }\end{array}$ \\
\hline $\begin{array}{l}\text { Roy KK study } \\
\text { (CTG monitoring) } \\
(\mathrm{n}=217)\end{array}$ & $\leq 30$ mins $(\mathrm{n}=121)$ & $26(21.4 \%)$ \\
\cline { 2 - 3 } $\begin{array}{l}\text { Present study } \\
\text { (inter-mittent }\end{array}$ & $\leq 30$ mins $(\mathrm{n}=96)$ & $7(7.2 \%)$ \\
$\begin{array}{l}\text { auscultation of } \\
\text { FHR) }(\mathrm{n}=150)\end{array}$ & $>30$ mins $(\mathrm{n}=90)$ & $25(27.77 \%)$ \\
\hline
\end{tabular}


In Roy KK study in which CTG monitoring was used, the rate of NICU admission was less than present study and Kenyatta hospital study (intermittent auscultation FHR). ${ }^{27}$

In present study there was no significant difference in immediate NICU admission whether the D-D (Detection of fetal distress to delivery interval) time interval was $\leq$ 30 minutes or $>30$ minutes.

In contrary to this in K.K. Roy study NICU admission in $\leq 30$ minutes group was significantly higher. ${ }^{27}$

But total NICU admission in Roy KK study (with CTG monitoring) the rate of NICU admission was 33 (15.2\%) and in present study (intermittent auscultation fetal heart rate) $41(27.33 \%)$ i.e. the rate of NICU admission was less in Roy KK study compared to present study.

\section{CONCLUSION}

Association of antenatal complications was high in study group compared to control group.Most common indication for induction of labour in study group was post-date pregnancy and control group was PIH.

Incidence of meconium stained liquor in study group was high. In study group incidence of NICU admission in first 48 hours and mortality was higher in thick meconium compared to thin meconium.

Clinical foetal distress (study group) was found to be significantly associated with low $1 \mathrm{~min}$ and $5 \mathrm{~min}$. Apgar Score. Incidence of NICU admission and mortality rate was high in first 48 hours in study group when compared to control group.

Most common indication for NICU admission in study group was MAS (Meconium aspiration syndrome). Most common cause of perinatal death in study group was MAS with HIE stag III with severe PNA.

There was no significant difference in immediate NICU admission whether D-D (i.e. detection fetal detection to delivery interval) time interval $<30$ minutes or $>30$ minutes. But rate of mortality was high when D-D (i.e. detection fetal detection to delivery interval) was > 30 minutes.

\section{Funding: No funding sources}

Conflict of interest: None declared

Ethical approval: Not required

\section{REFERENCES}

1. Maharaj D. Intrapartum fetal resuscitation: a review. The Internet J Gynecol Obstet. 2008;9(2):414-e1.

2. Bobrow CS, Soothill PW. Causes and consequences of fetal acidosis. Arch Dis Child Fetal Neonatal Ed. 1999;80:246-9.
3. Mukhopadhyay P, Naskar T, Dalui R, Hazra S, Guin $\mathrm{K}$, Bhattacharya $\mathrm{D}$. Role of intrapartum amnioinfusion in meconium stained amniotic fluid. J Obstet Gynaecol India. 2006;56:230-2.

4. Sudharma RJ. Fetal compromise: Update in anesthesiology. Manual of Pediatric Intensive Care E-Book pre and postoperative guidelines by Manoj Luthra, Elsevier; 2012:3-7. Available at: http://update.anesthesiologist.org.wp.content.

5. Parer JT, Livingston EG. What is fetal distress? Am J Obstet Gynecol. 1990;162:1421-7.

6. Miller D, Birthrites. Healing After Caesarean. Topic Four- Foetal Distress and Monitoring. What is Foetal Distress? First part, Available at: www.birthrities.org/fetalDistress\&B.html.

7. Morabito, CJ, DiCarlo JV. Neonatal Irespiratory failure Imeconium aspiration syndrome from textbook, Department of Paediatrics, Lucile Packard Children's Hospital, Stanford University, California. (Highly Recommended Reading - DM).

8. McNamara H, Johnson N, Lilford R. The effect on fetal arteriolar oxygen saturation resulting from giving oxygen to the mother measured by pulse oximetry. Br J Obstet Gynaecol. 1993;100:446-9.

9. Goodlin, RC. Importance of the lateral position during labor. Obstet Gynecol. 1971;37:698-701.

10. Abitbol MM, Monheit AG, Poje J, Baker MA. Nonstress test and maternal position. Obstet Gynecol. 1986;66:310-6.

11. Nathan EB, Haberman S, Burgess T, Minkoff H. The relationship of maternal position to the results of brief nonstress tests: a randomized clinical trial. Am J Obstet Gynecol. 2000;182:1070-2.

12. Cito G, Luisi S, Mezzesimi A, Cavicchioli C, Calonaci G, Petraglia, F. Maternal position during non-stress test and fetal heart rate patterns. Acta Obstet Gynecol Scand. 2005;84:335-8.

13. Leighton BL. Anaesthetic complications: intraoperative. In: Obstetric Anesthesia Norris MC (ed), JB Lippincott Co. Philadelphia; 1993:616-618.

14. Howard BK, Goodson JH, Mengert WF. Supine hypotensive syndrome in late pregnancy. Obstet Gynecol. 1953;1:371.

15. Waldron KW, Wood C. Cesarean section in the lateral position. Obstet Gynecol. 1971;37:706-10.

16. Levy DM. Emergency caesarean section: best practice. Anaesth. 2006;61:786-91.

17. Kinsella SM. Lateral tilt for pregnant women: why 15 degrees? (Editorial). Anaesth. 2003;58(9):835-6.

18. Crino JP, Harris AP, Parisi VM, Johnson RB. Effect of rapid intravenous infusion on uteroplacental blood flow and placental implantation-site oxygen delivery in the pregnant ewe. Am J Obstet Gynecol. 1993;168:1603-9.

19. Steer PJ, Danielian P. Fetal distress in labour. In: James DK, Steer PJ, Weiner CP, Gonik B (eds). High Risk Pregnancy Management Options. $2^{\text {nd }}$ ed. London: WB Saunders; 1999:1121-1149. 
20. Briozzo L, Alma M, Nozar M, Fiol V, Pons J, Alonso J. Tocolysis and delayed delivery versus emergency delivery in cases of non-reassuring fetal status during labor. J Obstet Gynaecol Res. 2007;33(3):266-73.

21. Hofmeyr GJ. Amnioinfusion for potential or suspected umbilical cord compression in labour, Cochrane Database Syst Rev. 2005;2:CD001182.

22. Mino M, Puertas A, Miranda JA, Herruzo AJ. Amnioinfusion in term labor with low amniotic fluid due to rupture of membranes: A new indication. Eur J Obstet Gynecol Reprod Biol. 1999;82:29-34.

23. Miyazaki FS, Nevarez F. Saline amnioinfusion for relief of repetitive variable decelerations: a prospective randomized study. Am J Obstet Gynecol. 1985; 153:301-6.

24. Geidam A, Bako B, Ibrahim S, Ashir M. Early neonatal outcome of babies delivered by cesarean section because of clinical diagnosis of fetal distress. The Int J Gynecol Obstet. 2010; 12(2):24-9.

25. Bhide SS, Shendurnikar N, Aiyer S, Baxi SR. Neonatal outcome after meconium stained amniotic fluid. J Obstet Gynecol India. 1993;44:933-5.
26. Rotich SK, Ndavu MP, Rukaria-Kaumbutho R, Kigondu CS. Early perinatal outcome in cases delivered through Caesarian section following clinical diagnosis of severe foetal distress at Kenyatta National Hospital. East African Med J. 2006;83(5):250-8.

27. Roy KK, Baruah J, Kumar S, Deorari AK, Sharma JB, Karmakar D. Cesarean section for suspected fetal distress, continuous fetal heart monitoring and decision to delivery time. The Indian $\mathrm{J}$ Pediatr. 2008;75(12):1249-52.

Cite this article as: Jadhav CA, Tirankar VR, Gavandi PS. Study of early perinatal outcome in lower segment caesarean section in severe foetal distress at tertiary care centre. Int J Reprod Contracept Obstet Gynecol 2020;9:1259-67. 